\title{
Transient Behavior of Burden Descending and Influence of Cohesive Zone Shape on Solid Flow and Stress Distribution in Blast Furnace by Discrete Element Method
}

\author{
Zhengyun FAN, ${ }^{1,2)}$ Shungo NATSUI, ${ }^{1)}$ Shigeru UEDA, ${ }^{1)}$ Tianjun YANG, ${ }^{2)}$ Junya KANO, ${ }^{1)}$ Ryo INOUE ${ }^{1)}$ \\ and Tatsuro ARIYAMA ${ }^{11}$
}

1) Institute of Multidisciplinary Research for Advanced Materials, Tohoku University, 2-1-1 Katahira, Aoba-ku, Sendai $980-8577$ Japan. $\quad 2$ 2) School of Metallurgical and Ecological Engineering, University of Science and Technology Beijing, No. 30 Xueyuan Road, Haidian Zone, Beijing 100083 P. R. China.

(Received on October 30, 2009; accepted on January 9, 2010)

\begin{abstract}
The present investigation intends to elucidate the transient behavior of burden descending, the influence of cohesive zone shape on the solid flow and the stress field through three-dimensional analysis by discrete element method (DEM) in blast furnace. Although many continuum models were developed to analyze the in-furnace phenomena such as solid flow, DEM enables to analyze the unsteady state solid flow, the stress distribution and slip of burden in the three dimensional state. In this study, it was clarified that the solid flow in blast furnace was composed of steady flow and transient flow which caused by burden charge and slip around raceway. Burden charge instantaneously causes high stress region and high velocity region to spread from upper part to lower part. High velocity region caused by slip around raceway spreads upwards and mitigates the stress field in the vicinity of raceway. The cohesive zone shape almost does not affect on the particle movement in the upper part of shaft and deadman shape. However, the distribution of high stress region and high slipping region is affected by the cohesive zone shape. Asymmetric high stress and slipping distribution are formed in the case of biased cohesive zone, and high cohesive zone enlarges the region of high stress. Weak slipping region in the upper part of shaft tends to be mitigated by the stress field in upper part. Belly receives the maximum stress from burden. The normal stress acting on the bottom is concentrated on the center of bottom by the buoyancy effect of pig iron in the hearth.
\end{abstract}

KEY WORDS: ironmaking; blast furnace; cohesive zone; solid flow; discrete element method; stress, slip.

\section{Introduction}

Recently, the low reducing agent operation in the large blast furnace is a serious subject in ironmaking of Japan. In such a condition, the control of burden flow in blast furnace has attracted a special attention. The solid flow in blast furnace greatly affects on the distribution of gas flow in the upper part of blast furnace, the motion of coke in the vicinity of raceway and deadman profile. Consequently, the controlling over the solid flow plays an important role in stabilizing the operation of blast furnace, especially in the large blast furnace under low reducing agent. ${ }^{1)}$ Some cold experiments with two- and three-dimensional model have been carried out to understand the behavior of solid flow in blast furnace. ${ }^{2-4)}$ However, although these results reflect the behavior of solid flow at macroscopic level, they can not present the unsteady state solid motion and stress distribution. Accordingly, the unstable and discontinuous phenomena at the particle level can not be derived by the above models.

Numerical simulation analysis for solid flow in blast furnace is a powerful tool to understand the behavior of solid flow. So far, there are two kinds of simulation approach: 1) continuum approach in which solid flow is regarded as a continuum phase; 2) Discrete Element Method (DEM). Although, continuum approach has been employed to simulate the solid flow in blast furnace for years, ${ }^{5,6}$ the results obtained can not reflect the microstructure and non-uniform behavior of solid flow. In DEM, the individual particle is modeled by tracking the motion of every particle based on interactive force between particles at every step time. Therefore, this method can be used to model the discontinuous phenomena and the non-uniform motion of the particle flow in an unsteady state at the microscopic level. Some researches have been carried out to study the solid motion in blast furnace by DEM. ${ }^{7-10)}$

In blast furnace, the descending motion of burden can be mainly divided to there characteristic regions as follows: 1 ) upper moving zone where particles have almost uniform velocity; 2) coke moving zone between the cohesive zone and deadman. 3) deaman consisting of only coke where particles of coke move stagnantly. The unbalanced descending behavior of solid flow in the circumferential direction could influence on these three characteristic regions. In the present paper, the influence of cohesive zone shape and the relationship among the particle velocity, stress and slip force distribution are discussed to clarify the total burden 
descending in blast furnace by DEM.

\section{Simulation Model}

\subsection{Governing Equation of DEM}

In DEM, all forces acting on each particle are modeled and calculated based on Voigt model consisting of springdashpot and a slider at every step time, as shown in Fig. 1(a). The interactive force between particles is shown in Fig. 1(b).

The normal force $F_{n, i h}$ and the tangential force $F_{t, i j}$ are derived as,

$$
\begin{array}{r}
F_{n, i j}=\left(K_{n} \Delta u_{n, i j}+\eta_{n} \frac{\Delta u_{n, i j}}{\Delta t}\right) n_{i j} \ldots \ldots \ldots \ldots \ldots . . . . . .(1) \\
F_{t, i j}=\min \left\{\mu\left|F_{n, i j}\right| t_{i j},\left[K_{t}\left(\Delta u_{t, i j}+\Delta \varphi_{i j}\right)+\eta_{t} \frac{\Delta u_{t, i j}+\Delta \varphi_{i j}}{\Delta t}\right] t_{i j}\right\}
\end{array}
$$

Where, $K, \eta$ and $\mu$ denote the spring coefficient, the damping coefficient and slid friction coefficient, respectively. $\Delta u$ and $\Delta \varphi$ denote the relative translational displacement of gravitational center between two particles and the relative angular displacement caused by rotation, respectively. $n_{i j}$ and $t_{i j}$ denote the unite vector from $i$-th particle to $j$-th particle in normal and tangential components. The subscript $n$ and $t$ denote the normal direction and tangential direction, respectively.

The trajectory of particle is obtained by the integration equation governing the translational motion and the rotational motion of a particle. The equations are shown as follow:

$$
\begin{gathered}
m \frac{d v}{d t}=\sum F_{n} \ldots \\
I \frac{d \omega}{d t}=\sum\left(T+M_{r}\right)
\end{gathered}
$$

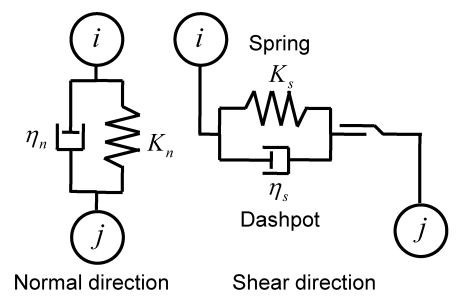

(a) The spring-dashpot contact model

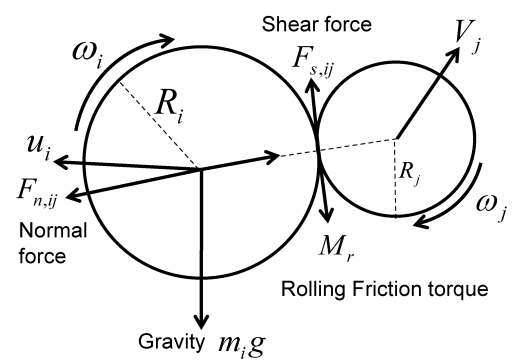

(b) Interactive force between two particles

Fig. 1. Interaction between two particles in DEM.
Where, $v, \omega$ denote the translational velocity and angular velocity, respectively. $m$ is the mass of a particle. $I$ denotes the moment of inertia of particle. $T$ denotes a torque which is generated by elastic tangential force and viscous tangential force. $M_{r}$ is rolling friction torque that resists the rotation of the particle. $F_{n}$ is the normal force acting on the particle.

\subsection{Simulation Condition}

In the present calculation, the solid behavior in $5000 \mathrm{~m}^{3}$ blast furnace with 40 tuyeres was simulated by DEM. The geometry of blast furnace used in calculation is shown in Fig. 2. The tap hole is placed at $4.4 \mathrm{~m}$ over bottom of blast furnace. The buoyancy effect of hot pig iron is taken into account and the level of hot pig iron is kept constant at $4.4 \mathrm{~m}$ over bottom of blast furnace in the present simulation. 40 tuyeres are set at $5.55 \mathrm{~m}$ from tap hole level with uniform interval. The shape of raceway is assumed to be elliptical shape with $2 \mathrm{~m}$ in length and $1.1 \mathrm{~m}$ in width. The particles that flow into raceway disappear at the specified interval. Melting behavior of ore is not considered in this article. A cohesive line denoting the cohesive zone is used in this simulation. Once the particles of ore descend across this line, they would disappear immediately. Therefore, there are only the particles of coke below the cohesive zone. The three different shapes of cohesive zone are proposed in this simulation as shown in Fig. 2. Cohesive zone (A) called as base cohesive zone is a symmetric cohesive zone with $8.6 \mathrm{~m}$ in height over tuyere level. Cohesive zone (B) is biased cohesive zone with $5 \mathrm{~m}$ biased distance from center of blast furnace. Height of biased cohesive zone is $8.6 \mathrm{~m}$ over tuyere level. Cohesive zone (C) is a high cohesive zone with 15 in height over tuyere level. The change of cohesive zone shape has an influence on solid flow and stress distribution. To reduce the computing time, semicircle model with 180 degree is chosen for simulation. The parameter of the cohesive zone used in DEM is listed in Table 1. The downward flow of burden due to gravity is driven mainly by the combustion of coke particle in raceway and disappearance of ore in cohesive zone. The stock line is placed at $25.3 \mathrm{~m}$ over tuyere level. Coke and ore are

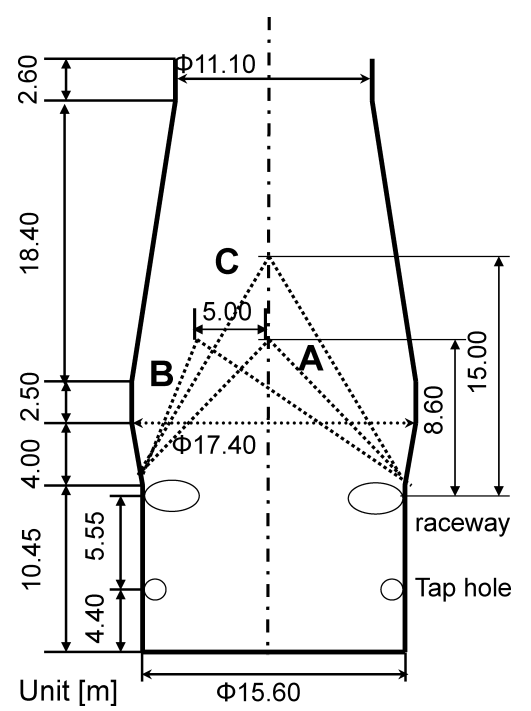

Fig. 2. Geometry of blast furnace used in DEM. 
Table 1. Parameter of cohesive zone in simulation.

\begin{tabular}{lcc}
\hline Order & $\begin{array}{c}\text { Biased distance } \\
\text { from center of BF }[\mathrm{m}]\end{array}$ & $\begin{array}{c}\text { Height over } \\
\text { tuyere level }[\mathrm{m}]\end{array}$ \\
\hline $\mathrm{A}$ (Base) & 0 & 8.6 \\
$\mathrm{~B}$ (Biased) & 5 & 8.6 \\
$\mathrm{C}$ (high) & 0 & 15 \\
\hline
\end{tabular}

Table 2. Properties of particle and variables in simulation.

\begin{tabular}{|c|c|c|}
\hline Parameter & Coke & Ore \\
\hline Diameter $d_{p}[m]$ & 0.4 & 0.2 \\
\hline Particle density $\rho_{\mathrm{s}}\left[\mathrm{kg} / \mathrm{m}^{3}\right]$ & 1100 & 4000 \\
\hline Young's modulus G [GPa] & 6.0 & 6.0 \\
\hline Poisson's ratio $v$ & 0.21 & 0.21 \\
\hline Frictional coefficient(p-p) $\mu$ & 1.2 & 1.2 \\
\hline Frictional coefficient(p-w) $\mu$ & 0.7 & 0.7 \\
\hline Rolling frictional coefficient $\alpha$ & 2.5 & 2.5 \\
\hline Time step $\Delta t[\mathrm{sec}]$ & \multicolumn{2}{|c|}{$10^{-4}$} \\
\hline Discharging rate at raceway $[1 / \mathrm{s}]$ & \multicolumn{2}{|c|}{165} \\
\hline Density of hot pig iron $\rho_{1}\left[\mathrm{~kg} / \mathrm{m}^{3}\right]$ & \multicolumn{2}{|c|}{6700} \\
\hline
\end{tabular}

charged alternately to keep the stock line in the same manner to the actual blast furnace. The diameters of coke and ore are $0.4 \mathrm{~m}$ and $0.2 \mathrm{~m}$, respectively. The appropriate parameters for coke and ore are selected by the repose angle calculated in DEM. ${ }^{10)}$ The properties of particle and variables in simulation are listed in Table 2.

\section{Feature of Burden Descending in BF}

\subsection{Burden Descending and Transient Particle Veloc- ity Change}

Ore and coke are charged alternately from throat to keep the stock line and discharged from raceway at specified interval to maintain steady solid flow. The calculated distributions of burden layer are shown in Fig. 3. In Figs. 3(A), 3(B) and 3(C) denote three cases for cohesive zone. Grey particle and red particle denote coke and ore, respectively. The coke free space is formed in the peripheral region close to the wall, due to the buoyancy of hot pig iron in hearth. It is found that only the particle in the lower central part contacts with the bottom of blast furnace. From these results, it is observed that the distribution of burden layer in upper shaft is not influenced by the cohesive zone shape, however the shape of cohesive zone slightly causes disturbance of burden layer in lower part of shaft due to the narrow distance between the cohesive zone and wall. Especially under the condition of biased cohesive zone of case (B), the shape of layer on both sides becomes asymmetric.

The instantaneous change of average particle velocity with time in three regions under the base cohesive zone condition which is calculated by DEM is shown in Fig. 4. The pentangle and circle denote ore charge and coke charge, respectively. Triangle denotes slip around raceway. To be precise, the average velocity of particles fluctuates with time, and the momentum of burden charge has an instantaneous influence on the particle velocity. Since the weight of ore charge is greater than that of coke charge, the influence of ore charge is remarkable on the average velocity. Looking at the instantaneous change of particle velocity

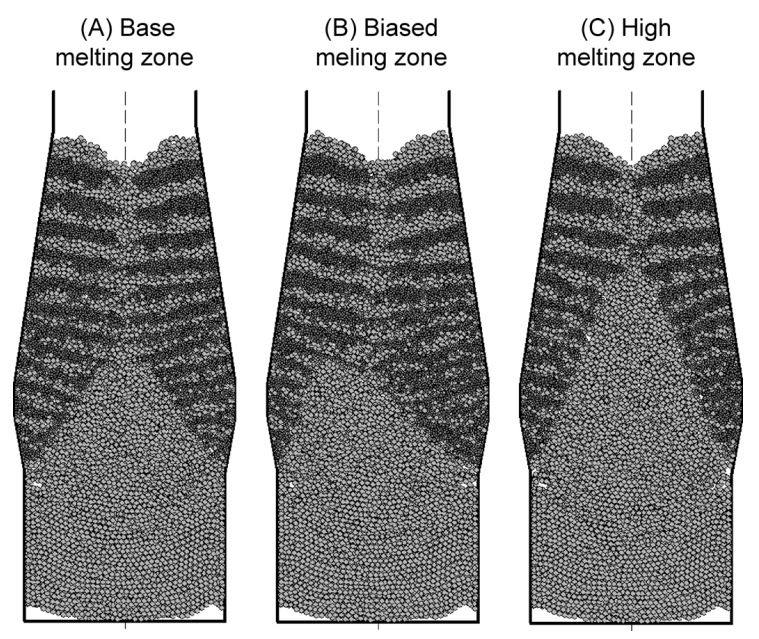

Fig. 3. Calculated burden layer distribution for each case in blast furnace by DEM.

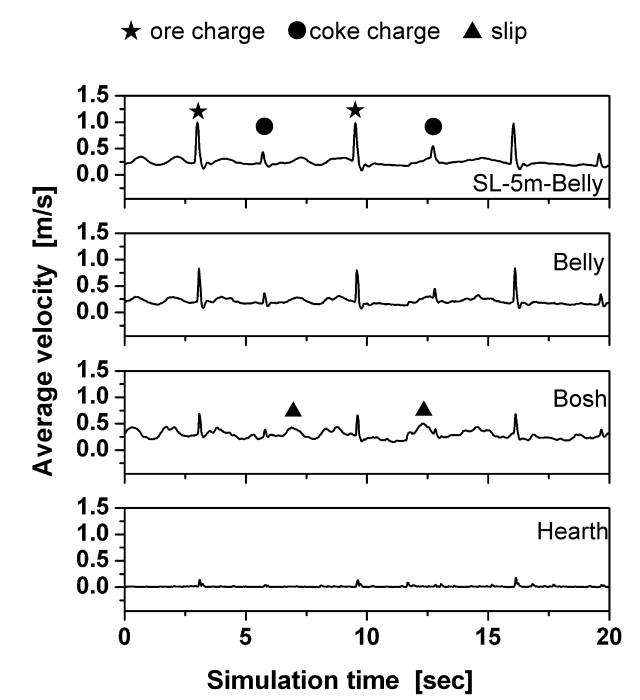

Fig. 4. Average velocity of particle in each part of blast furnace under base cohesive zone condition (A).

after charging, the influence of burden charge on average velocity spreads from upper part to lower part of blast furnace and weakens gradually. That is because that burden structure in the lower part supports upper burden and causes the decrease of velocity.

Slight slip can be observed in Fig. 4. Slip around raceway causes the increase in particle average velocity in bosh as shown in Fig. 4. Contrary to the burden charge, the influence of slip spreads from bosh to upper part and increases the velocity of local particles. Thus, it is estimated that the solid flow in blast furnace consists of steady descending flow and transient flow caused by burden charge and slip around raceway. The average velocity of particle under the different cohesive zone condition is shown in Fig. 5. It is observed that the motion of burden in blast furnace is still composed of steady flow and transient flow, and the shape of cohesive zone does not affect on the mode of solid motion in blast furnace.

Figure 6 shows the transient change of particle velocity at ore charge and coke charge under the condition of base cohesive zones calculated by DEM. The numeral below snapshot denotes time in simulation. Since the burden is in- 


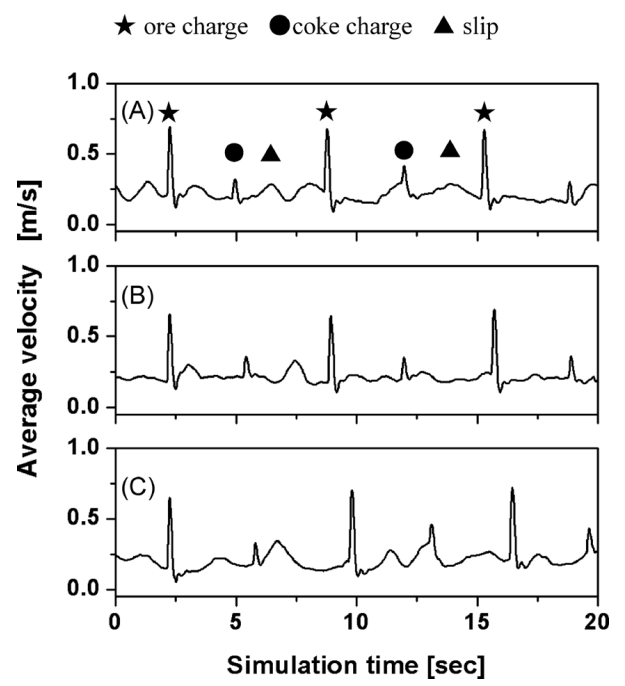

Fig. 5. Average velocity of particle under different cohesive zone condition from SL-5 $\mathrm{m}$ to bottom.

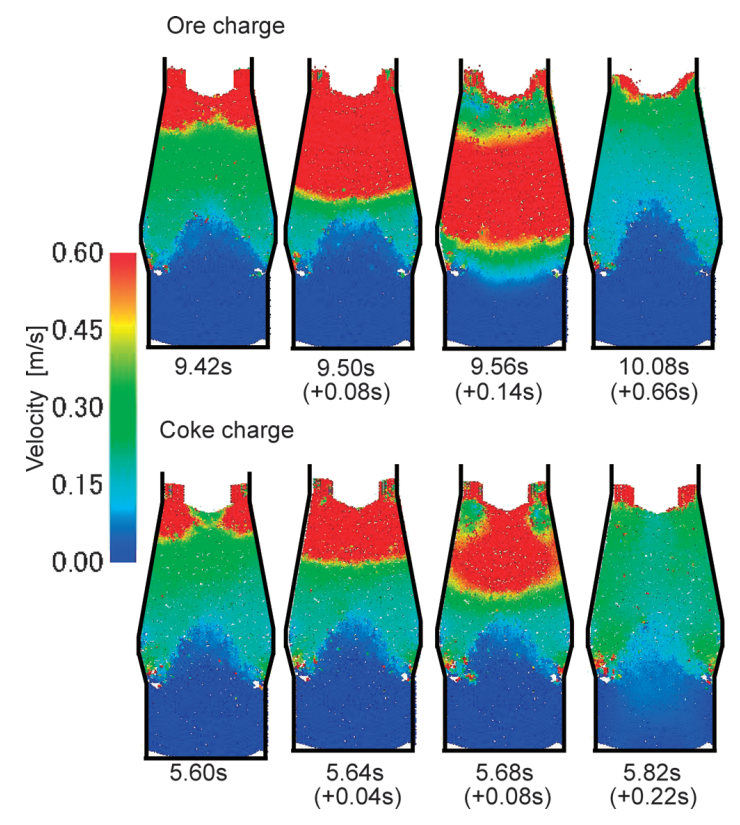

Fig. 6. Transient change of particle velocity after ore and coke charge in case (A).

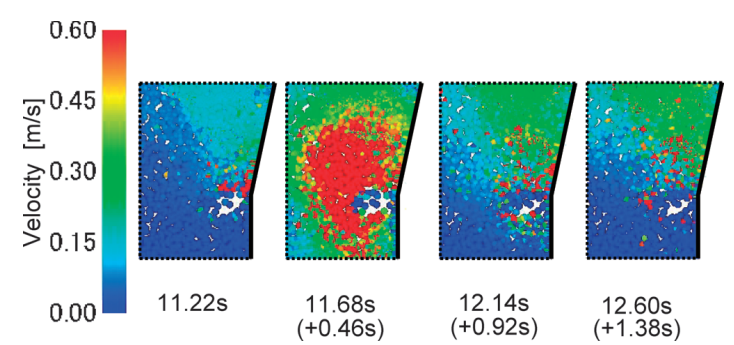

Fig. 7. Variation of particle velocity caused by slip around raceway.

stantaneously charged from throat, high velocity region in red is firstly formed at the upper part of shaft, and then spreads to lower part until steady descent. The variation of particle velocity caused by slip around raceway is shown in Fig. 7. Since the stagnant zone and moving zone coexist in the vicinity of raceway, non-uniform motion caused by slip occurs frequently, which generates more void among parti-

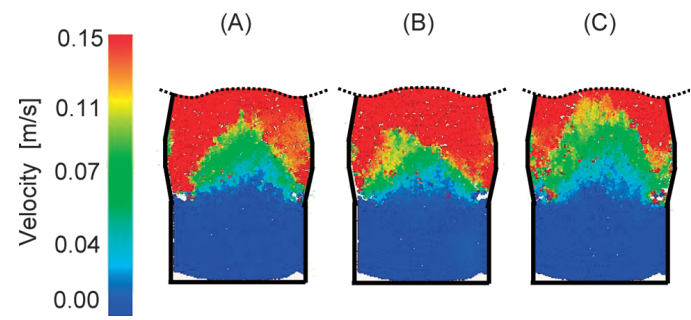

Fig. 8. Distribution of particle velocity at steady descent.

cles and causes the increase of particle velocity in the vicinity of raceway. As shown in Fig. 7, high velocity region denoted by red enlarges and it instantly fades. It is estimated that these phenomena are derived from the stress distribution and the packed state of material in blast furnace.

\subsection{Velocity Distribution in Lower Part}

The velocity distribution of particle in the lower part of blast furnace at steady descent is shown in Fig. 8. In Figs. $8(\mathrm{~A}), 8(\mathrm{~B})$ and $8(\mathrm{C})$ correspond to the velocity distribution in the case of base cohesive zone, biased cohesive zone and high cohesive zone, respectively. It is observed that the velocity field can be divided into four characteristic regions: 1) funnel flow region with high velocity shown in red; 2) coke moving zone with medium velocity shown in yellow and green; 3) deadman with stagnant coke velocity shown in deep blue; 4) quai-stagnant zone adjacent to the deadman shown in light blue. It is observed that deadman exists in the lower central part of blast furnace and the shape of deadman is almost not influenced by the cohesive zone shape in every case. The shape of coke moving zone corresponds to the shape of cohesive zone. An asymmetric medium velocity region is formed in lower part under the condition of biased cohesive zone. High cohesive zone enlarges the medium velocity region to upper part. Accordingly, it is estimated that the shape of deadman is almost independent on the cohesive zone and coke moving zone is influenced by the melting behavior of burden.

\section{Distribution of Stress between Particles}

Normal stress $\sigma_{n}$ and shear stress $\sigma_{t}$ are derived as Eq. (5) and Eq. (6), respectively,

$$
\begin{aligned}
& \sigma_{n}=\left(\sum F_{n, i j}\right) /\left(\pi D_{i}^{2}\right) \\
& \sigma_{t}=\left(\sum F_{t, i j}\right) /\left(\pi D_{i}^{2}\right) .
\end{aligned}
$$

Where, $F_{n, i j}$ and $F_{t, i j}$ are normal force and shear force acting on the particle $i$, respectively. $D_{i}$ is the diameter of particle $i$. Variation of average normal stress, shear stress and velocity with time in the case of base cohesive zone (A) are shown in Fig. 9. In Fig. 9(a), 9(b) and 9(c) denote average velocity of particles from $5 \mathrm{~m}$ below stock line to bottom, normal stress and shear stress from $5 \mathrm{~m}$ below stock line to upside of belly and that below upside of belly, respectively. It is observed that normal stress is greater than shear stress in every part. The normal and shear stress in lower part are higher than those in shaft. The influence of ore charge on normal and shear stress is more remarkable than that of 


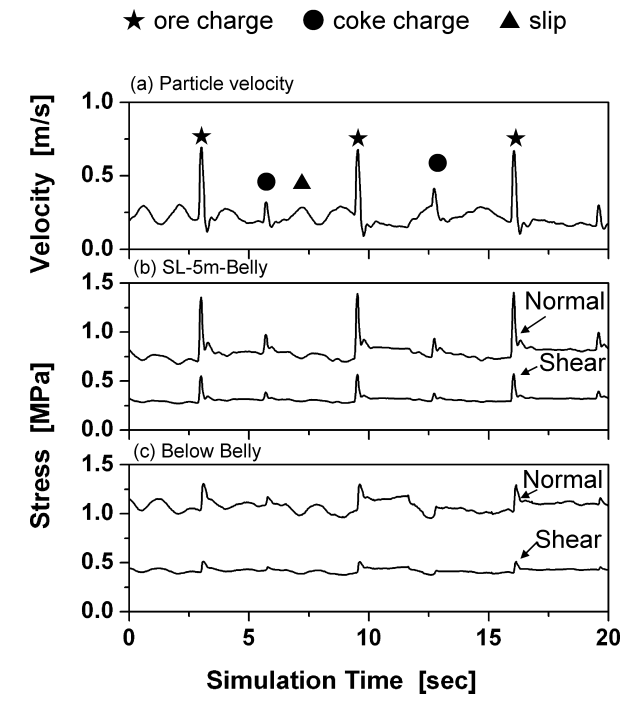

Fig. 9. Variation of normal stress and shear stress with time in case (A).
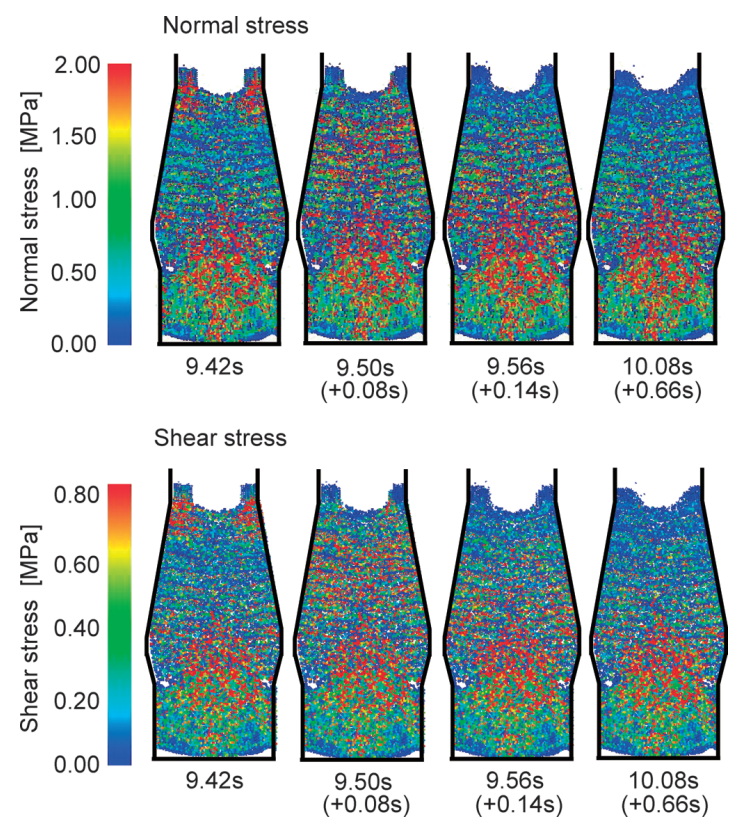

Fig. 10. Distribution of normal and shear stress at burden charge.

coke charge. They all cause the increase in normal and shear stresses. Since slip around raceway can generate more void among particles, it is interacted with the formation of stress network and results in the decrease of normal stress and shear stress, as show in Fig. 9.

The distribution of normal and shear stress between particles at ore charge in case (A) is shown in Fig. 10. High normal and shear stress are denoted in red. From these snapshots, it is found that high normal and shear stress region are instantaneously formed at upper part of shaft at charging, and then gradually spread downwards. The distribution of stress in the lower part is slightly influenced by burden charge, and almost stable for charging. some particles in bosh and deadman receive the maximum normal stress over $2 \mathrm{MPa}$ and shear stress over $0.8 \mathrm{MPa}$, as shown in red. The tendency of changing of normal and shear stress agrees with the changing of particles velocity, shown in Fig. 6.

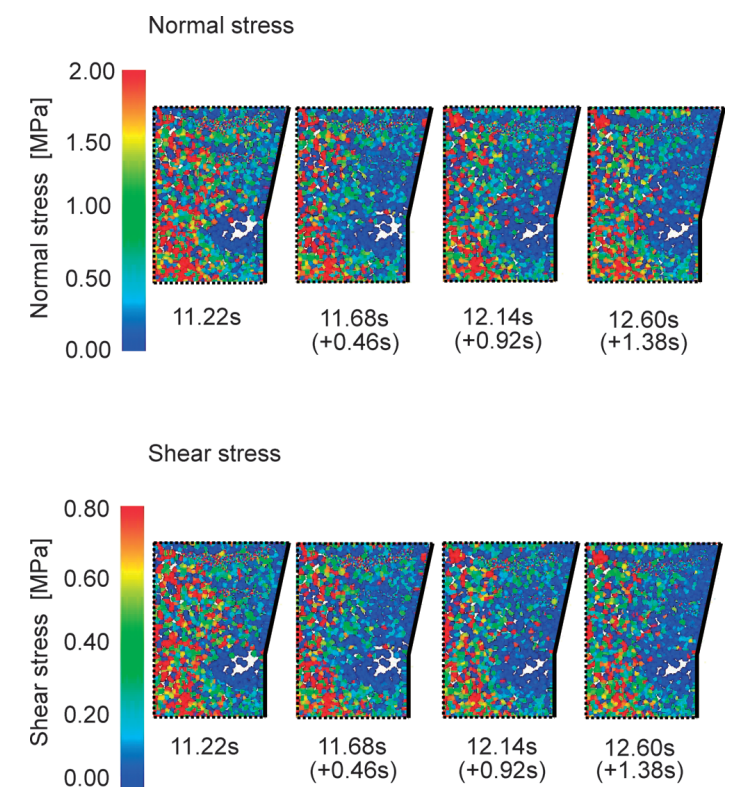

Fig. 11. Distribution of normal and shear stress at slip around raceway.
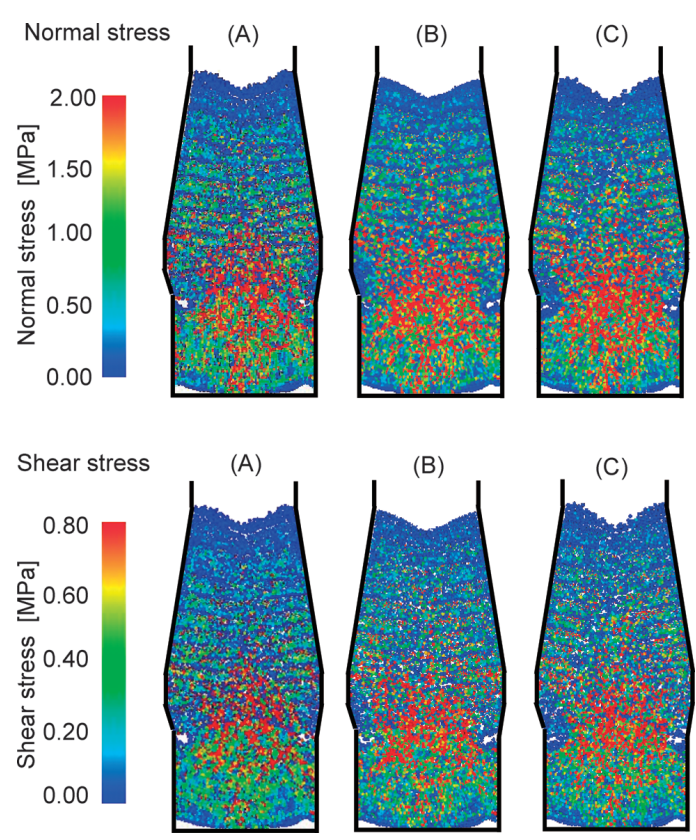

Fig. 12. Distribution of normal and shear stress at steady descent.

Figure 11 shows the normal stress and shear stress distribution at slip around raceway. Slip around raceway instantaneously increases the particle velocity nearby slip region as shown in at $+0.46 \mathrm{~s}$ of Fig. 7 , then slip changes the structure of stress field and mitigates the stress around raceway. In Fig. 11, it is observed that high stress region denoted in red simultaneously disappear in the vicinity of raceway. This phenomenon at $+0.46 \mathrm{~s}$ of Fig. 11 corresponds to Fig. 7. Thus, it is deduced that the high velocity region caused by slip around raceway corresponds to the low stress filed. The shear stress in Fig. 11 is similar to the change of transient particle velocity in Fig. 7.

Figure 12 shows the normal and shear stress distribution at steady state in vertical cross section. In Figs. 12(A), 12(B) and 12(C) correspond to base cohesive zone, biased 
cohesive zone and high cohesive zone, respectively. It is observed that the complicated stress networks are formed in blast furnace. The stress distribution in the present simulation shows more complicated network than the result of Nouchi et $a l .{ }^{7)}$ It is estimated that the differences between them are derived from the condition of particle hardness and assumption of boundary condition of wall. In the Nouchi's research, due to the usage of a model with 10 degrees, the stress distribution obtained would be affected easily by the wall. Moreover, he used soft particle in his simulation. In the case of soft particle hardness, the network tends to be consistent if the contact conditions between particles are formed. In addition, only the particles of coke were used in the Nouchi's research, which would also results in the consistent stress distribution and less stress between particles. Especially, the present study is based on the semicircle model with $180^{\circ}$ for high accuracy and coke and ore particles with the realistic particle hardness. Therefore, the results obtained are more complicated and is able to reflect the situation in blast furnace with high accuracy.

The particles in the upper part of shaft and around raceway exhibit weak stress field. This is because the particles in these regions move fast and there exists more voids, which results in decrease of the contact among particles. High stress region exists in the lower part of blast furnace and corresponds to coke moving zone. Stress distribution at belly in horizontal cross section is shown in Fig. 13. Comparing these results, it is found that an asymmetric high normal and shear stress region are formed in the case of biased cohesive zone, as shown in Fig. 12(B) and Fig. 13(B). High cohesive zone enlarges the central high stress region, as shown in Fig. 12(C) and Fig. 13(C). It is estimated that the structures of layers of ore and coke have influence on the stress distribution.

Figure 14 shows the distribution of normal and shear stress between particles in the central cylindrical region with $3 \mathrm{~m}^{2}$. Vertical axis and horizontal axis denote height from tuyere level and stress, respectively. From these results, it is found that the maximum normal stress exists in bosh around $7 \mathrm{~m}$ from tuyere level in case (A) and (B), however the maximum normal stress shows in the region about $2.5 \mathrm{~m}$ over tuyere level in case (C), due to the small amount of ore in shaft. Moreover, the value of the stress in the center becomes smaller towards bottom in each case. The distribution of shear stress between particles with height shows the same tendency with that of normal stress. These general tendencies along longitudinal axis are similar to the results of the previous study by elastic-plastic theory, ${ }^{11)}$ although the calculation methods are different each other.

\section{Distribution of Slip Force}

The motion of particles in blast furnace is composed of the translational motion and rotation based the theory of DEM. The sliding and rolling friction are taken into account in the present simulation. According to Coloumb's law of friction, if the force in the tangential direction is greater than the product of sliding friction coefficient and force in the normal direction, the particle would slip. Here, slip force is defined as follow:

$$
F_{\mathrm{Sli}}=F_{t, i j}-\mu F_{n, i j}
$$

Thus, if $F_{\text {Sli }}>0$, the particle slips. The slip force is shown in Fig. 15. Figures 15(A), 15(B) and 15(C) correspond to base cohesive zone, biased cohesive zone and high cohesive zone, respectively. Green and red circle denote slipping particle. Non-slipping particles are denoted by deep blue circle. It is observed that the most slipping particles exist in the boundary of layers of the upper part of blast furnace, and there are less slipping particles in deadman. This phenomenon indicates that relative slip among particles occurs infrequently in deadman, and the particles in deadman keep relatively static. In addition, weak slipping particles existing in the upper part of shaft, especially on the border of burden layers mitigate the formation of stress network in the upper part and result in the stress network in lower part, as shown in Fig. 12. Due to the existence of deadman below the coke moving zone, the particles in coke moving zone move with the low velocity and high stress. Comparing with the particles in upper part, the particles in coke moving zone move in non-linear way, which generate high slipping particles denoted by red color.

\section{Distribution of Normal Stress Acting on the Wall and Bottom}

\subsection{Distribution of Normal Stress Acting on the Wall}

Normal stress acting on the wall is calculated by the following equation:

$$
\sigma_{n, w}=4 F_{n, i w} /\left(\pi D_{i}^{2}\right)
$$

Where, $F_{n, i w}$ denotes normal force acting on the wall by particle $i$. $D_{i}$ denotes the diameter of particle $i$. The distribution of normal stress acting on the wall with height at steady state is shown in Fig. 16. Here, Fig. 16(A), 16(B) and $16(\mathrm{C})$ correspond to the base cohesive zone, biased cohesive zone and high cohesive zone, respectively. Tuyere level is shown at $0 \mathrm{~m}$. Belly is set from 4.5 to $7 \mathrm{~m}$ over tuyere level. It is observed that belly receives the maximum normal stress in every case, which agrees with the measurement by Shimizu et al. ${ }^{12)}$ Due to the buoyancy of hot pig iron, normal stress below tuyere level shows the non-uniform distribution. The maximum value concentrated on the region about $2.5 \mathrm{~m}$ below tuyere level in every case. The influence of cohesive zone on the normal stress acting on the wall is not observed.

The variation of normal stress acting on the wall in the case of base cohesive zone at ore charge is shown in Fig. 17. The number below snapshot corresponds to simulation time. It is observed that the normal stress acting on the wall is partly influenced by ore charge. Since ore is charged form the throat, the normal stress acting on the wall firstly increases and then spreads downwards. However, the influence of ore charge is limited in the wall above tuyere level, and the wall below tuyere level hardly is affected by ore charge at every time. Belly always receives the maximum stress from burden at every time.

\subsection{Distribution of Normal Stress Acting on the Bot- tom}

Due to the buoyancy of hot pig iron, the coke free space 


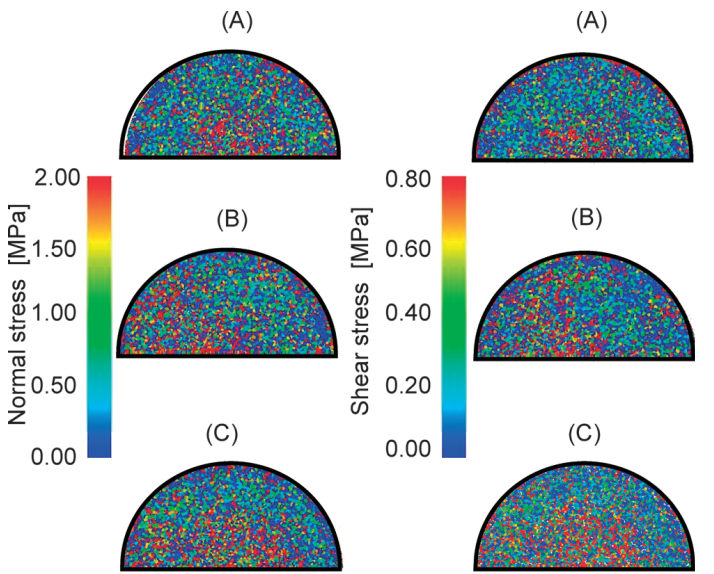

Fig. 13. Normal and shear stress distribution at belly level in horizontal cross section.
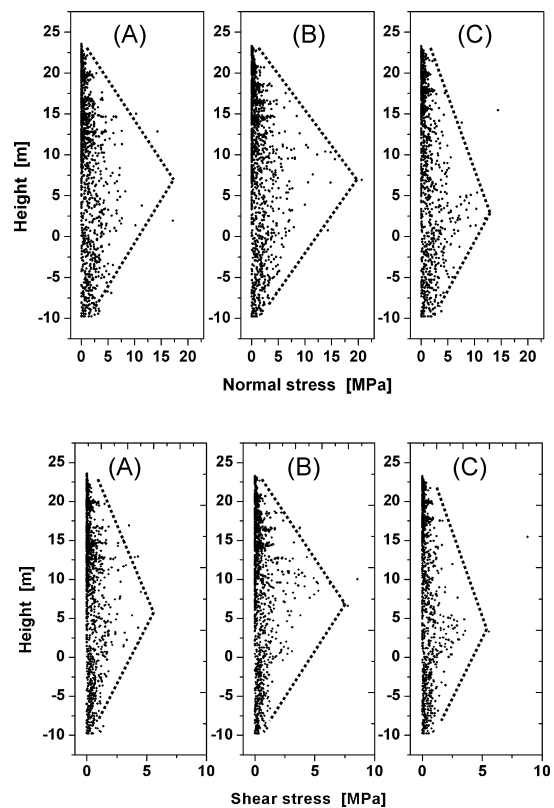

Fig. 14. Stress distribution in the center part with height from tuyere level.
(A)

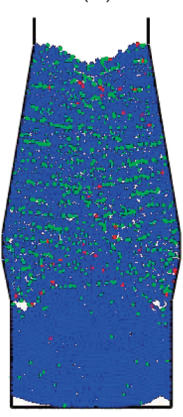

(B)

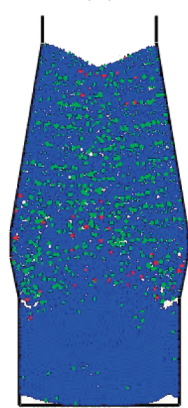

Slip force $F_{\text {si }}[K N]$

- $\mathrm{F}_{\mathrm{si}}>11 \mathrm{KN}$

$0 \mathrm{KN}<\mathrm{F}_{\mathrm{si}}<11 \mathrm{KN}$

- $\mathrm{F}_{\mathrm{si}}<\mathrm{OKN}$
(C)

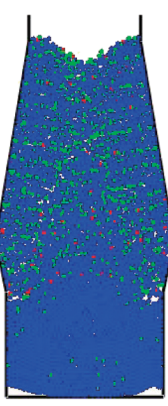

Fig. 15. Distribution of slip force under different cohesive zone condition.

is formed at the peripheral region close to the wall, as shown lower white region in Fig. 3. Only the particles in the lower center contact with bottom. The normal stress is de-

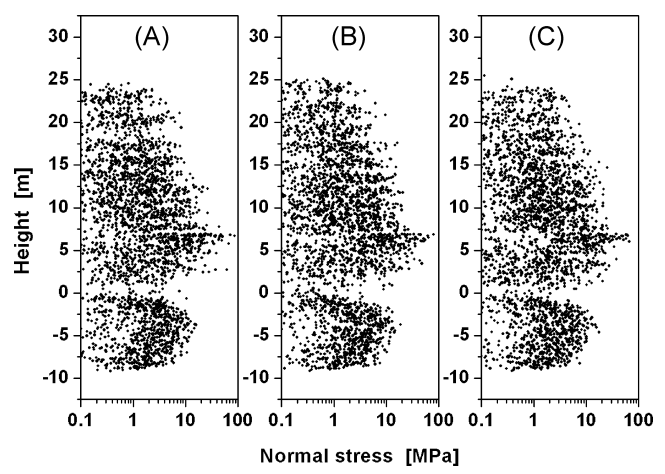

Fig. 16. Stress distribution on surface of wall with height from tuyere level.
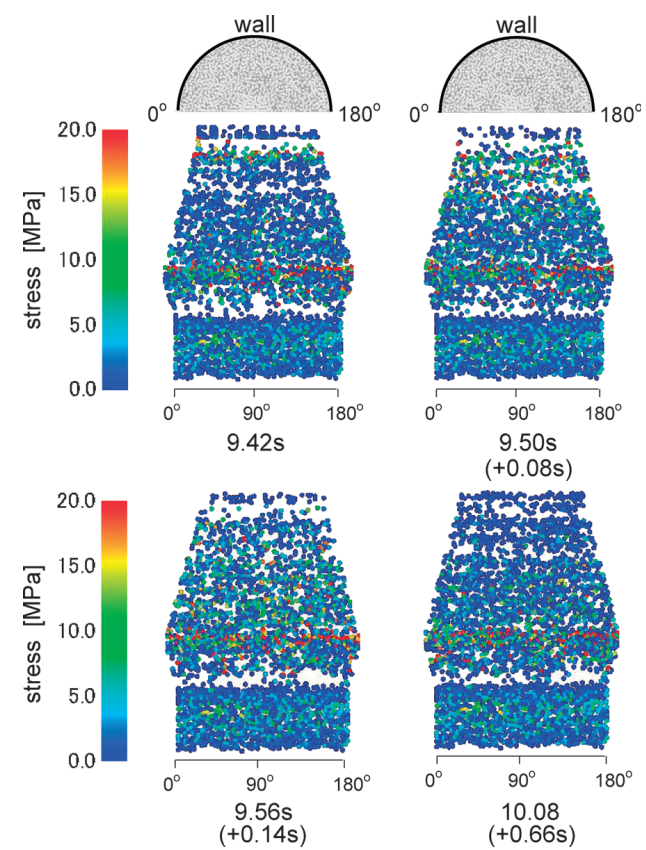

Fig. 17. Variation of normal stress at ore charge.
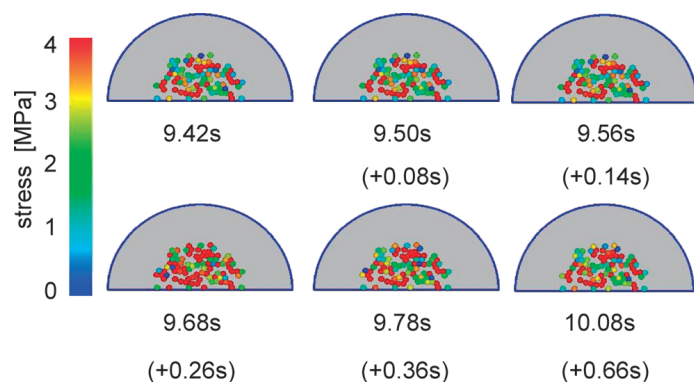

$9.56 \mathrm{~s}$

$(+0.08 \mathrm{~s})$

$(+0.14 s)$

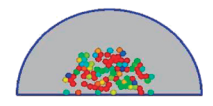

$9.78 \mathrm{~s}$

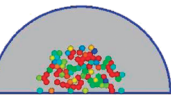

$10.08 \mathrm{~s}$

$(+0.36 s)$

$(+0.66 s)$

Fig. 18. Distribution of normal stress acting on bottom.

rived from Eq. (8). The distribution of normal stress acting on the bottom in the case of base cohesive zone is shown in Fig. 18. Grey region denotes non-contacting region with bottom. Circle denotes the location of contact point with bottom and color denotes the magnitude of normal stress. Numeral below the snapshot represents the time in simulation. It is observed that particles contacting with bottom concentrate on the center of bottom. From 9.42 to $9.56 \mathrm{~s}$, the normal stress acting on the bottom does not changes re- 
markably, however, at $9.68 \mathrm{~s}$ the normal stress increases obviously, as shown the increase of red particles. Afterwards, the normal stress decreases gradually. This phenomenon indicates that due to the combined effects of particle movement and buoyancy of hot pig iron, stress acting on the bottom increases instantaneously, and decreases gradually.

\section{Conclusions}

Three-dimensional discrete element method (DEM) has been employed to investigate the transient behavior of burden descending and the influence of cohesive zone shape on solid flow and stress distribution in blast furnace. The following results were obtained.

(1) It is confirmed that macroscopic solid flow in blast furnace is composed of steady flow and transient flow in unsteady state caused by burden charge and slip around raceway. Burden charge instantaneously causes the increase of particle movement and stress, however slip around raceway mitigates the stress field and causes the increase of void and particle velocity. The influence of burden charge spreads downwards from the upper part of shaft, on the contrary, the influence of slip around raceway is limited to narrow region.

(2) The shape of coking moving zone corresponds to the cohesive zone. The particle movement in upper shaft and shape of deadman is not affected by the cohesive zone shape. The complicated stress network is formed in the lower part of blast furnace. The coke moving zone and deadman exist in high stress region. The shape of cohesive zone influences remarkably the distribution of high stress region. Asymmetric high stress region is formed in the case of biased cohesive zone and high cohesive zone enlarges the high stress region in the center.

(3) According to the results of slip force, most of slipping particles exist above deadman, and weak slipping par- ticles on the borders of burden layers interacts with the formation of stress network in upper part of blast furnace. It is estimated that slip force between layers mitigates the stress formation.

(4) The normal stress acting on the wall is not influenced by the shape of cohesive zone. Belly receives the maximum normal stress. Due to the buoyancy of hot pig iron, normal stress below tuyere level shows non-uniform distribution in height. Due to the buoyancy of hot pig iron, the particles of coke nearby wall float and do not contact with bottom. The particles of coke on the center contact with bottom. Therefore, the normal stress acting on the bottom is concentrated on the center and slightly varies with time.

\section{REFERENCES}

1) T. Ariyama, R. Murai, J. Ishii and M. Sato: ISIJ Int., 45 (2005), 1371.

2) M. Shimizu, Y. Kimura, M. Isobe, C. Che and S. Inaba: Tetsu-toHagané, 73 (1987), 1996.

3) H. Takahashi, H. Kawai, M. Kobayashi and T. Fukui: ISIJ Int., 45 (2005), 1386.

4) A. Shinotake, M. Ichida, H. Ootsuka and Y. Kurita: Tetsu-to-Hagané, 89 (2003), 573.

5) J. A. De Castro, H. Nogami and J. Yagi: ISIJ Int., 42 (2002), 44.

6) H. Nogami, M. Chu and J. Yagi: Comput. Chem. Eng., 29 (2005), 2438.

7) T. Nouchi, T. Sato, M. Sato, K. Takeda and T. Ariyama: ISIJ Int., 45 (2005), 1426.

8) Z. Zhou, H. Zhu, A. Yu, B. Wright, D. P and P. Zulii: ISIJ Int., 45 (2005), 1828.

9) H. Mio, K Yamamoto, A. Shimosaka, Y. Shirakawa and J Hidaka: ISIJ Int., 47 (2007), 1745.

10) S. Natsui, S. Ueda, M. Oikawa, Z. Fan, J. Kano, R. Inoue and T. Ariyama: ISIJ Int., 49 (2009), 1308.

11) K. Katayama, S. Wakabayashi, T. Inada, K. Takatani and H. Yamaoka: Tetsu-to-Hagané, 83 (1997), 91.

12) M. Shimizu, A. Yamaguchi, S. Inaba and K. Narita: Tetsu-toHagané, 68 (1982), 936. 